[6] Avouac J, et al. Diagnostic and predictive value of anti-cyclic citrullinated protein antibodies in rheumatoid arthritis: a systematic literature review. Ann Rheum Dis 2006; 65:845

Disclosure of Interests: None declared

DOI: 10.1136/annrheumdis-2019-eular.7550

\section{AB0271 FACTORS ASSOCIATED WITH HOSPITAL ADMISSIONS MORTALITY IN RHEUMATOID ARTHRITIS PATIENTS IN SPAIN. (TREND-AR STUDY)}

Ramón Mazzucchelli ${ }^{1}$, Elia Perez-Fernandez ${ }^{2}$, Javier Quirós ${ }^{3}$, Virginia Villaverde ${ }^{4}$ Alberto García-Vadillo ${ }^{5}$, Marina Peña ${ }^{6}$, Carmen Barbadillo $^{7}$, Cristina Macía-Villa ${ }^{8}$, Jose Luis Morell Hita ${ }^{9}$, Hilda Godoy ${ }^{7}$, Manuel Fernandez-Prada ${ }^{10}$, María GalindoIzquierdo ${ }^{11}$, Angeles Herranz Varela ${ }^{12}$, Concepción Morado Quiroga ${ }^{13}$, María Espinosa ${ }^{14}$, Cristina Martinez-Prada ${ }^{13}$, Natalia Crespí-Villarías ${ }^{15}$. ${ }^{1}$ Hospital Universitario Fundación Alcorcón, Rheumatology, Alcorcón, Spain; ${ }^{2}$ Hospital Universitario Fundación Alcorcón, Clinical Investigation Unit, Alcorcón, Madrid, Spain; ${ }^{3}$ Hospital Universitario Fundación Alcorcón, Rheumatology, Alcorcón, Spain; ${ }^{4}$ Hospital Universitario de Móstoles, Rheumatology, Móstoles, Spain; ${ }^{5}$ Hospital de La Princesa, Madrid, Spain; ${ }^{6}$ Hospital Universitario Fundación Alcorcón, Rehabilitation, Alcorcón, Spain; ${ }^{7}$ Hospital Puerta de HierroMajadahonda, Rheumatology, Majadahonda, Spain; ${ }^{8}$ Hospital Universitario de Leganés, Rheumatology, Leganés, Madrid, Spain; ${ }^{9}$ Hospital Ramón Y Cajal, Rheumatology, Madrid, Spain; ${ }^{10}$ Hospital Universitario de Guadalajara, Rheumatology, Guadalajara, Spain; ${ }^{11}$ University Hospital 12 de Octubre, Rheumatology, Madrid, Spain; ${ }^{12}$ Hospital Henares, Coslada, Spain; ${ }^{13} \mathrm{Hospital}$ Clinico Universitario San Carlos, Madrid, Spain; ${ }^{14}$ Infanta Sofia University Hospital, Rheumatology, San Sebastián de los Reyes, Spain; ${ }^{15}$ Health Center Rivota, Alcorcón, Spain

Background: There have been significant changes in the management of rheumatoid arthritis (RA) during the past 20 years. The potential impact of these changes on hospital admissions mortality is unknown.

Objectives: To analyse the factors associated with hospital admissions mortality in rheumatoid arthritis patients in Spain from 1999 to 2015.

Methods: This is a retrospective population study. We have analized a national administrative database that includes a Minimum Basic Data Set (MBDS) of hospital admissions of RA patients during the period 1999 to 2015 . We studied all the cases of hospital admissions mortality. Patients were identified by concatenation of clinical record number and birth date. The analyzed factors were identified by the presence in primary and secondary diagnosis of the ICD9 codes, during the first hospital admission. Hazard Ratio (adjusted by sex and age) were calculated using Cox regression analyses.

Results: There were a total of 338.343 hospital admissions in RA patients during the study period, accounting for a total of 186.491 patients (127.203 women $(68,21 \%)$ and 59.288 men $(31,79 \%)$. The mean number of hospital admissions was 1,81(SD 1,7), with a minimum of 1 and a maximum of 43 . The median time of follow-up was 11,85 months (DE 27,4). There were a total of 18.641 exitus $(5,5 \%)$. The HR (adjusted by sex and age) of the factors associated with hospital admissions mortality are shown in the next table:

\begin{tabular}{lccc}
\hline Risk factor & \multicolumn{3}{c}{ Adjusted by sex and age Cox reg analyses } \\
\hline & $\mathrm{HR}$ & $\mathrm{IC}$ & $\mathrm{p}$ \\
\hline Gender (Male/Female) & 1,242 & $1,20-1,28$ & $<0,001$ \\
Age & 1,066 & $1,064-1,068$ & $<0,001$ \\
Charlson Index & 1,276 & $1,268-1,284$ & $<0,001$ \\
Stay & 1,004 & $1,003-1,005$ & $<0,001$ \\
Cardiovascular disease & 1,318 & $1,274-1,362$ & $<0,001$ \\
Dementia & 1,852 & $1,696-2,021$ & $<0,001$ \\
Diabetes Mellitus & 1,093 & $1,05-1,137$ & $<0,001$ \\
Neoplasm & 2,432 & $2,313-2,556$ & $<0,001$ \\
Hepatopathy severe-moderate & 3,189 & $2,752-3,695$ & $<0,001$ \\
COPD & 1,113 & $1,071-1,156$ & $<0,001$ \\
Pressure ulcers & 1,115 & $1,006-1,235$ & 0,036 \\
Renal Disease & 1,758 & $1,683-1,837$ & $<0,001$ \\
Infectious disease during stay & 1,593 & $1,545-1,642$ & $<0,001$ \\
S. Felty & 1,531 & $1,18-1,985$ & $<0,001$ \\
Amyloidosis & 2,957 & $2,627-3,327$ & $<0,001$ \\
Hip fracture & 0,731 & $0,664-0,804$ & $<0,001$ \\
Tuberculosis & 1,066 & $1,064-1,068$ & $<0,001$ \\
\hline
\end{tabular}

Conclusion: In Spain, during the period of 1999-2015, the factors associated with hospital admission mortality (first admission) are: age, male sex, higher Charlson Index and longer hospital stay. The associated clinical variables are chronic hepatopathy, amyloidosis and neoplasm.

Disclosure of Interests:

None declared
DOI: 10.1136/annrheumdis-2019-eular.2270

\section{AB0272 EVALUATION OF CXCL13, SICAM-1, MMP-3 AND S100A8/A9 AS SERUM BIOMARKERS IN PATIENTS WITH RHEUMATOID ARTHRITIS TREATED WITH SUBCUTANEOUS TOCILIZUMAB}

D. James Haddon, Thierry Sornasse, Michael J. Townsend, Jinglan Pei, Margaret Michalska. Genentech, Inc., South San Francisco, United States of America

Background: Serum levels of C-X-C motif chemokine ligand 13 (CXCL13) and soluble intercellular adhesion molecule-1 (sICAM-1) have been associated with response to tocilizumab (TCZ) in patients with rheumatoid arthritis (RA); levels of matrix metalloproteinase-3 (MMP-3) and S100A8/A9 have also been associated with RA disease activity and joint damage.

Objectives: To evaluate the association of CXCL13, SICAM-1, MMP-3 and s100A8/A9 levels with disease activity and response to TCZ in patients with RA who achieved low disease activity with 24 weeks of TCZ + methotrexate (MTX) treatment and were subsequently randomized to TCZ monotherapy (mono) or TCZ + MTX in the COMP-ACT trial (NCT01855789).

Methods: US patients with RA who had an inadequate response to MTX received initial combination therapy of MTX plus TCZ $162 \mathrm{mg}$ subcutaneous for 24 weeks. Patients who achieved Disease Activity Score in 28 joints calculated with erythrocyte sedimentation rate (DAS28-ESR) $\leq 3.2$ at Week 24 were randomized 1:1 (double-blind) to receive either TCZ mono or continue TCZ + MTX until Week 52. Randomized patients were included in the present study based on baseline, Week 24 and Week 40 sample availability; serum levels of CXCL13, sICAM-1, MMP-3 and S100A8/A9 were measured by immunoassay. Correlations between CXCL13, sICAM-1, MMP-3 and S100A8/A9 levels and DAS28-ESR at baseline, Week 24 and Week 40 were determined according to Spearman correlation coefficient. Changes in CXCL13, SICAM-1, MMP-3 and S100A8/ A9 levels from baseline to Week 24 (open-label period) were determined using Wilcoxon test. Mean changes in CXCL13, sICAM-1, MMP-3 and S100A8/A9 levels from Week 24 to Week 40 (randomized period) were compared between treatment arms using analysis of covariance.

Results: Of 296 randomized patients, 249 were included (TCZ mono, $\mathrm{n}=$ 126; TCZ + MTX, $\mathrm{n}=123$ ). Biomarker levels were well balanced across treatment arms at baseline and Week 24 (randomization). At baseline there were weak to mild correlations between DAS28-ESR and biomarker levels (CXCL13 $[r=0.13, P=0.0411]$, sICAM-1 $[r=0.20, P=0.0015]$ MMP-3 $[r=0.19, P=0.0021]$, S100A8/A9 $[r=0.25, P=0.0001])$. Significant reductions in mean biomarker levels were observed from baseline to Week 24 (open-label period) among the total randomized patients $(P$ $<0.0001$ ). CXCL13, SICAM-1, MMP-3 and S100A8/A9 levels were relatively stable between Week 24 and Week 40 (randomized period), with no significant differences between TCZ mono and TCZ + MTX (Table).

\begin{tabular}{|c|c|c|c|c|}
\hline & \begin{tabular}{|l|} 
Dose $Q 1$ \\
21.00 to $1.735 \mathrm{mg}$ \\
$\mathrm{N}=184$
\end{tabular} & \begin{tabular}{c|}
$\begin{array}{c}\text { Dose } Q 2 \\
\text { > }\end{array}$ \\
$>13.75$ to $\leq 25.00 \mathrm{mg}$ \\
$N=184$
\end{tabular} & $\begin{array}{c}\text { Dose Q3 } \\
>25.00 \text { to } 4 \text { 40.00 } \mathrm{mg} \\
\mathrm{N}=198\end{array}$ & $\begin{array}{l}\text { Dose } 04 \\
>40 \mathrm{mgg} \\
\mathrm{N}=161\end{array}$ \\
\hline $\begin{array}{l}\text { Patients without type } 2 \text { diabetes and without } \\
H b A 1 c \geq 7.5 \text { in the pre-index perrod, }\end{array}$ & 120 & 136 & 130 & 110 \\
\hline $\begin{array}{l}\text { Wint type e diabetes didagnosis or HbA1c } 27.5 \\
\text { in the post-index period, } n(\%)\end{array}$ & $\theta(7.5)$ & $16(11.8)$ & $16(12.3)$ & $27(24.5)$ \\
\hline $\begin{array}{l}\text { Maximum HbA1c value across HbA1c lab results } \\
\text { during post-index, mean (SD) }\end{array}$ & $7.75(246)$ & $8.30(2.86)$ & $8.25(2.42)$ & $8.61(3.09)$ \\
\hline 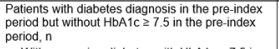 & & 18 & 40 & 15 \\
\hline $\begin{array}{l}\text { With worsening diabeles with HbA1c } 27.5 \text { in } \\
\text { the post-index period, } n(\%)\end{array}$ & $10(32.3)$ & $6(33.3)$ & $20(50.0)$ & $4(26.7)$ \\
\hline \begin{tabular}{|l|}
$\begin{array}{l}\text { Pationts without blood glucose level } 2200 \mathrm{mg} / \mathrm{dL} \\
\text { in the pre-index period, } n\end{array}$ \\
\end{tabular} & 173 & 169 & 179 & 147 \\
\hline $\begin{array}{l}\text { With blood glucose level z 200mg//LL in the } \\
\text { postindex period, } n(\%)\end{array}$ & $13(7.5)$ & $15(8.9)$ & $24(13.4)$ & $22(15.0)$ \\
\hline \multicolumn{5}{|l|}{ Adverse events in the post-index period, $\mathrm{n}(\%)$} \\
\hline $\begin{array}{l}\text { Serious infection requiring hospitalization for } \\
\text { infection and Io IV a atioiotics }\end{array}$ & $31(16.8)$ & $39(21.2)$ & $44(22.2)$ & $40(24.8)$ \\
\hline Serious infection requiring IV antibiotics & 29 (15.8) & $33(17.9)$ & $42(21.2)$ & $35(21.7)$ \\
\hline $\begin{array}{l}\text { Serious infection requiring hospitalization } \\
\text { for infection }\end{array}$ & $6(3.3)$ & $12(6.5)$ & $12(6.1)$ & $8(5.0)$ \\
\hline Cataracts & $22(12.0)$ & $27(14.7)$ & $34(17.2)$ & $35(21.7)$ \\
\hline 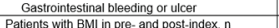 & $\frac{11(6.0)}{171}$ & $\frac{11(6.0)}{162}$ & & $\frac{19(11.8)}{141}$ \\
\hline $\begin{array}{l}\text { Patients with BMI in pre-and post-index, } \mathrm{n} \\
\text { Increase in BMI by } 5, \mathrm{n}(\%)\end{array}$ & $\begin{array}{l}171 \\
7(4.1)\end{array}$ & $\begin{array}{c}162 \\
5(3.1)\end{array}$ & $\begin{array}{l}181 \\
9(5.0)\end{array}$ & $\begin{array}{l}141 \\
9(6.4)\end{array}$ \\
\hline
\end{tabular}

Conclusion: In agreement with previous studies, the association between baseline disease activity and CXCL13, sICAM-1, MMP-3 and S100A8/A9 levels was weak to mild; TCZ + MTX treatment from baseline to Week 24 (open-label period) resulted in significant reductions in all biomarkers. Changes in levels of CXCL13, sICAM-1, MMP-3 and S100A8/A9 from Week 24 to 40 (randomized period) were similar between treatment groups, consistent with the finding of non-inferiority of TCZ mono compared with TCZ + MTX in patients with RA who achieve low disease activity with TCZ + MTX.

Acknowledgement: This study was funded by Genentech, Inc.

Disclosure of Interests: D. James Haddon Shareholder of: Stockholder of Genentech/Roche, Employee of: Employee of Genentech/Roche, Thierry 